\title{
MRI rectal cancer in Australia and New Zealand: an audit from the PETACC- 6 trial
}

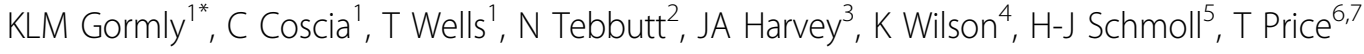 \\ From International Cancer Imaging Society Meeting and 15th Annual Teaching Course (ICIS 2015) \\ London, UK. 5-7 October 2015
}

\section{Introduction}

An MRI audit substudy was conducted of patients who underwent an MRI prior to treatment in Australia and New Zealand as part of the international PETACC-6 trial in locally advanced rectal cancer.

\section{Method}

82 patients of the 127 Australasian patients from 15 centres had rectal MRI scans reviewed for technique, data included in reports and comparison of reports with blinded central reporting by 2 experienced radiologists.

\section{Results}

$82 \%$ performed minimum T2 sagittal and T2 axial oblique sequences. The high resolution T2 sequence parameters varied significantly with only $33 \%$ obtaining a voxel size of $\leq 1.3$. The rate of inclusion of relevant findings in the reports was; T3 distance in $\mathrm{mm} 21 \%, \mathrm{~N}$ stage $84 \%$, CRM status $72 \%$, EMVI status $29 \%$ and distance from the puborectalis sling $17 \% .31 \%$ of reports included all of; T stage with T3 substage, $\mathrm{N}$ stage and CRM involvement. $17 \%$ of reports included these 3 findings and EMVI. Eleven reports used a template with $82 \%$ of these including the first 3 findings. The agreement with central reporters was $\mathrm{T}$ stage $76 \%, \mathrm{~N}$ stage $70 \%$, CRM status $57 \%$ and EMVI 16\%.

\section{Conclusion}

There is significant variation in scan quality and low rates of inclusion of all clinically relevant findings in rectal MRI reports reviewed for this audit. The authors recommend adoption of routine sequences and template reports to improve scan technique and report accuracy in rectal cancer MRI staging scans across Australia and New Zealand.

Dr Jones and Partners Medical Imaging, Adelaide, Australia

Full list of author information is available at the end of the article

\section{Authors' details}

${ }^{1}$ Dr Jones and Partners Medical Imaging, Adelaide, Australia. ${ }^{2}$ Olivia NewtonJohn Cancer and Wellness Centre, Austin Health. Melbourne, Melbourne, Australia. ${ }^{3}$ Princess Alexandra Hospital, Woolloongabba, Australia. ${ }^{4} \mathrm{NHMRC}$ Clinical Trials Centre, University of Sydney, Sydney, Australia. ${ }^{5}$ Martin Luther University, Halle, Germany. ${ }^{6}$ The Queen Elizabeth Hospital, University of Adelaide, Adelaide, Australia. ${ }^{7}$ AGITG, Australia.

Published: 2 October 2015

doi:10.1186/1470-7330-15-S1-P44

Cite this article as: Gormly et al:: MRI rectal cancer in Australia and New Zealand: an audit from the PETACC-6 trial. Cancer Imaging 2015 15(Suppl 1):P44.
Submit your next manuscript to BioMed Central and take full advantage of:

- Convenient online submission

- Thorough peer review

- No space constraints or color figure charges

- Immediate publication on acceptance

- Inclusion in PubMed, CAS, Scopus and Google Scholar

- Research which is freely available for redistribution
() Biomed Central 